actividad apícola en si misma, los productores generan vinculaciones afectivas con respecto al "recurso abeja" que están mediatizadas por valoraciones simbólicas de la actividad, lo cual respondería a los altos niveles de autonomía relativa que caracterizan y diferencian el trabajo apícola de otros trabajos agrícolas. Tal como los apicultores individualmente significan el recurso abeja, los apicultores agrupados significan el concepto de organización productiva, pues además de los aspectos tocantes a la producción y venta de productos, ellos vivencian las organizaciones a las que pertenecen como espacio de interacción social y construcción de vínculos interpersonales; esto es, aún cuando el aspecto productivo de dichas organizaciones es considerado como un factor de suma relevancia, los apicultores en su mayoría valoran principalmente factores no directamente productivos, tales como el acceso a personas y espacios nuevos, a nuevas experiencias educativas o simplemente a las posibilidades que ofrecen las organizaciones de crear vínculos con otros apicultores.

\section{2) Segunda etapa.}

En esta segunda etapa, y a partir de las conclusiones de la primera, se estructuró un trabajo de investigación-acción participativo que tomó la forma de talleres, realizados en las regiones VIII, IX y X, con el objetivo de generar un modelo organizacional propio y en los que participaron apicultores representantes de organizaciones con las que se había trabajado en la etapa anterior.

El sistema de trabajo colaborativo se basó en la metodología Interaccional Integrativa (MII), lo que permitió acoger y sistematizar las experiencias, conocimientos e intereses de los apicultores participantes para resolver las problemáticas involucradas en la consecución del objetivo.

El producto de esta co-construcción entre investigadora y apicultores, es un modelo organizacional en el cual se sintetizan los análisis, propuestas y proyecciones del colectivo, configurando un referente inédito en tanto implica una propuesta de intervención diseñada a partir del proceso de reflexión e intercambio de experiencias de los sujetos a quienes la intervención va dirigida.

Agro Sur 35(1): 13-16 2007

\title{
DESAFÍOS REGIONALES DE LAS REDES DE PEQUEÑOS PRODUCTORES RURALES.
}

\section{REGIONAL CHALLENGES FOR NETWORKS OF SMALL RURAL PRODUCERS}

\author{
John W. Durston \\ Antropólogo Social, jdurston@mi.cl \\ Palabras clave: Agricultura familiar campesina (AFC), red, desafíos
}

Para ser exitosa, una organización en red de pequeños productores necesita incorporar a su estrategia, la dimensión territorial. Los desafíos y oportunidades para este tipo de organización de la sociedad civil son muy diferentes en diversas escalas territoriales. No basta con la simple distinción que suelen realizar los planificadores centralistas, entre la escala nacional y la escala "local". Con este término se limitar a mirar el nivel municipal, ocultando las pequeñas comunidades micro-locales al interior de cada comuna y las redes interpersonales que las unen. Tampoco han recibido adecuada atención los aspectos determinantes de las redes a niveles mayores que la comuna, correspondientes a las provincias y las regiones.

En esta presentación se analizan tres grandes desafíos que una Red enfrenta a nivel territorial regional el desafío de : 
- Dinamizar las relaciones internas con sus asociados;

- Fortalecerse como actor social en el mundo político y frente al Estado; y

- Implementar acciones que aporten beneficios a corto y mediano plazo a sus asociados.

Se presentan puntos de vista sobre los contenidos de estos desafíos, se reflexiona sobre su naturaleza y se presentan algunas sugerencias para la discusión.

\section{El desafío de dinamizar sus relaciones internas con sus asociados.}

\subsection{Comunicaciones y motivación de la membresía.}

Aunque la concreción de alianzas con asociaciones hermanas en otras regiones es una meta de corto plazo importante para alcanzar mayor representatividad e impacto, el tejido social interno de la RPPBA no se ha densificado con la profundidad e intensidad esperadas en sus inicios. Estudios realizados en otros países, indican que donde las organizaciones campesinas han sido reprimidas y/o cooptadas en su historia reciente, es necesario bajar de escala para fortalecer las organizaciones locales antes de (o al mismo tiempo que) subir de escala para tener impacto como actor social.

Esto significa que dirigentes, profesionales y promotores vayan a cientos de aldeas, a Juntas de Vecinos rurales, Comunidades Indígenas, Comités y Empresas Asociativas, etc. Significa priorizar recursos para capacitación organizativa de líderes y bases locales. Significa, en resumen, recordar que en este contexto territorial, local no es sinónimo de 'comunal', sino que las Asociaciones son parte del aumento de escala de la asociatividad, que debe emerger de un gran número de iniciativas en pequeñas comunidades.

El reclutamiento y la movilización de números mucho mayores de miembros de la asociación debe tomar en cuenta la heterogeneidad de sus potenciales miembros. Hay al menos dos grandes ejes. Uno es la diferencia cultural entre la idea de 'comunidad' en el pueblo Mapuche $y$ en el mundo de los colonos. El otro tema de análisis pendiente, es el del relevo generacional: muchos propietarios son de avanzada edad, y debe establecerse una estrategia para incorporar y empoderar a miembros más jóvenes: sus hijos e hijas.

En relación al tema de relevo generacional, deben explorarse mecanismos y acuerdos para que los hijos/as adultos sean sujetos de crédito y de subvención, con la anuencia de los padres, y socios con voz y voto en la asociación regional.

Un activo intangible a fortaleceres la importancia del patrilinaje en la organización comunitaria Mapuche y en los nexos territoriales religiosos y de parentesco entre muchas comunidades Mapuche, como los allyarehue y los lofmapu.

Uno de los grandes activos de la RPPBA es su carácter pluriétnico. Es una de las pocas instancias de la sociedad civil en que representantes del Pueblo Mapuche y de comunidades no-indígenas luchan por demandas e ideales compartidos. Por ende, el resultado de un diálogo intercultural de saberes sobre el bosque, debe ser el fortalecimiento de vínculos personales de confianza, reciprocidad y afecto entre líderes de ambos pueblos.

\subsection{Aumento de escala.}

Sin embargo, no es suficiente fortalecer la institucionalidad de los pequeños propietarios de bosque solamente al nivel de la comunidad local: es necesario "aumentar de escala" la asociatividad para superar muchos de los obstáculos y aprovechar las oportunidades para que las pequeñas comunidades realicen su potencial papel en la gestión sustentable de bosque.

"Para crear respeto para la asociatividad es necesario tener poder de regateo, lo que a su vez requiere algún grado de aumento de escala de la organización más allá del nivel local".

Fox continúa: "...el aumento de escala es especialmente importante para la representación de intereses de poblaciones dispersas, ya que ellos tienen grandes dificultades para definir intereses comunes y son los más vulnerables a los intentos desde arriba a dividir y vencerles". Más concretamente, Fox identifica diversas maneras específicas en que las asociaciones regionales pueden aportar al empoderamiento de la población campesina:

"-las organizaciones regionales pueden facilitar 
la acción colectiva en defensa de los intereses compartidos, mediante la superación de las restricciones socialmente construidas que son las solidaridades locales restringidas.

-Las organizaciones locales suelen carecer de poder de contrapeso al de las élites locales, mientras que las organizaciones nacionales suelen ser menos representativas de las diversidades...

-Las regionales combinan la fuerza potencial de una mayor escala de operación con vínculos más cercanos a sus bases locales.

-En las sociedades en que las mayorías carecen de acceso a medios independientes de comunicación masiva, las organizaciones regionales autónomas son, con frecuencia, las únicas fuentes de transmisión de información sobre los problemas compartidos."

En una publicación reciente se desarrollan argumentos teóricos en torno a tres problemas comunes a estas "organizaciones demembresía":

Dispersión Territorial: las organizaciones regionales presentan problemas importantes de la manutención de vínculos y comunicaciones con las comunidades de base, lo que exige mayores recursos humanos y financieros de lo que usualmente disponen estas organizaciones. 'Polizontes': la misma dispersión geográfica en combinación con la relativa homogeneidad de los productos de las empresas campesinas hacen más probable que surjan muchos 'free riders': individuos egoístas que se benefician de los derechos y mercados logrados por los esfuerzos de las directivas de la organización, sin dedicar ellos mismos tiempo y esfuerzo a la construcción social de esos bienes colectivos y públicos. En estas circunstancias, es especialmente difícil reclutar grandes números de miembros y lograr que asistan y que participen activamente.

Ley De Hierro De La Oligarquía Organizacional: en un clásico de la sociología política, estableció que las dirigencias de las organizaciones políticas de base tendrán siempre a burocratizarse, distanciarse de los grupos locales. '...los líderes de grandes organizaciones de membresía necesariamente desarrollan sus propios intereses, y eso incrementa su autonomía respecto a la base. Esa poderosa tendencia socava a veces la democracia interna...'.

Las redes horizontales dentro de y entre estos grupos regionales, a su vez, tienen la capacidad para contrarrestar la "ley de hierro de las oligarquías dirigentes" que es inherente a las organizaciones de membresía piramidales.

Si bien estos desafíos dificultan el surgimiento de asociaciones regionales campesinas poderosas, estas mismas investigaciones recientes muestran que no constituyen 'dilemas' sin solución. El problema de la dispersión geográfica, por ejemplo, está cediendo a las nuevas formas de capital social ${ }^{2}$ que nacen de las tecnologías de informática y comunicación (TIC), concretamente la telefonía rural y celular, el correo electrónico y la Web, todos de relativamente bajo costo monetario. Hay cierta claridad, entonces, en cuanto a las dinámicas específicas de un círculo virtuoso que deben producirse simultáneamente y en forma interactiva, para que emerja una organización campesina regional fuerte:

Condiciones de Éxito de Organizaciones Regionales Campesinas

-Superar las 'solidaridades excluyentes' locales -Confrontar las élites oligárquicas regionales, sin perder lazos con las bases

-Socializar rápidamente información relevante para sus estrategias

-Alianza con funcionarios progresistas de nivel medio y bajo

-Espacios creados desde arriba son ocupados por movilizaciones desde abajo

-Coproducción en redes entre funcionarios, organizaciones campesinas y otros actores de la sociedad civil nacional e internacional

\subsection{Rendición de cuentas a las bases.}

El peligro de oligarquización de la dirigencia es mayor en el caso chileno, por la práctica del Estado y de los medios de comunicación de adoptar a algún 'vocero' de sectores populares como los campesinos del bosque, para expresar sus opiniones en foros, debates y negociaciones, como si representaran a un conjunto homogéneo. En este contexto y con

\footnotetext{
${ }^{2}$ El contenido de confianza, reciprocidad y cooperación que se encuentra en algunas relaciones e instituciones socioculturales, que constituye un activo intangible para las personas que participan en éstas.
} 
estas prácticas, el liderazgo es representativo más que representante. Representa en el sentido de compartir objetivos y problemas con personas en situaciones parecidas. No obstante, en el caso de la RPPBA, los dirigentes sí han recogido en numerosos diálogos los pormenores y variantes de estas inquietudes de las bases, para explicarlas frente a autoridades y otros interlocutores.

Finalmente, como señala Fox, 'La ley de hierro de la oligarquía es más una fuerte tendencia que una ley todopoderosa'. Se puede reducir este distanciamiento entre los dirigentes y las bases, a través del debate amplio interno para llegar a una postura de la organización propiamente tal. Este debate y los mecanismos horizontales y verticales de rendición de cuentas (accountability) son claves para mantener la democracia interna y, en base a ella, ser un actor social de peso regional y nacional. Para eso, se necesita una combinación de mecanismos y de grupos intermedios de contraloría social en la organización:

'La existencia de mecanismos internos de rendición de cuentas horizontal, tales como las instancias intermedias de participación... son complementos esenciales de las estructuras convencionales de rendición de cuentas vertical dentro de las organizaciones sociales... En ausencia de subgrupos participatorios, los líderes de las grandes organizaciones tratan solamente con individuos atomizados, que, por lo general, no disponen de la oportunidad para compartir información que genera opiniones alternativas, contrapropuestas y líderes potenciales. En contraste, los subgrupos participatorios pueden incrementar el poder de sus integrantes (rendición de cuentas vertical), a través de la supervisión del funcionamiento de los líderes y la mediación entre los miembros votantes y los líderes.'

Agro Sur 35(1): 16-21 2007

\title{
MESA APÍCOLA NACIONAL, INSTANCIA DE ARTICULA- CIÓN PÚBLICO PRIVADA, ACCIONES DESARROLLADAS DESDE SU ORIGEN.
}

\section{NATIONAL APICULTURE ORGANIZATION, PUBLIC AND PRIVATE COLLABORATIONS, GOALS AND ACTIONS SINCE ITS CREATION}

\author{
Jeannette Danty Larraín \\ Oficina de Estudios y Políticas Agrarias (ODEPA), Ministerio de Agricultura, Chile
}

Palabras clave: Mesa Apícola, ODEPA.

\section{HISTORIA}

La apicultura nacional históricamente se ha desarrollado en forma muy atomizada, dado que sus productores están distribuidos entre la II y la XI regiones por infinidad de lugares localizados en muchas ocasiones, en las zonas más apartadas del territorio. Esta dispersión ha existido no sólo geográficamente y entre apicultores, sino también entre los distintos actores que componen la cadena agroalimentaria apícola, existiendo una desconfianza permanente entre productores y exportadores y entre pares. Más aislado se encontraba el sector académico y público del sector productivo, con absoluta inexistencia de instancias de articulación o coordinación.

El mundo apícola en Chile está compuesto 